\title{
OROZCO Y SUS PINTURAS DE "LOS MONOTES"
}

Por Xavier Moyssén

Al referirse Justino Fernández a las primeras obras de José Clemente Orozco, escribió lo siguiente:

Orozco pintaba con gran habilidad cartones y dibujos, que regalaba a sus amigos, en los que recogía escenas de burdel o tópicos callejeros y que constituyen un eslabón importante para entender su desenvolvimiento artístico; porque en esas emocionantes pinturas y dibujos, algunos de los cuales son ilustraciones para periódicos, ejecutados en la segunda década del siglo, así como en sus pinturas del café "Los monitos" (1916), se puede comprobar cómo desde entonces ya estaba perfilado, de cuerpo entero, el Orozco de 1922 y años siguientes...1

Como Justino Fernández no conoció el tal café, no aclaró si se trataba de pinturas murales o de caballete. Por lo demás el establecimiento a que se refiere fue el segundo que Orozco decoró en sus obras, pues existió otro, por lo menos hasta 1924, con el título de "Los monotes", se encontraba en la calle de República de Cuba, cercano al Teatro Lírico. Quienes se han ocupado de estudiar la obra del artista han olvidado o bien ignorado, la existencia de las pinturas y dibujos de los dos cafés; sin embargo, no deja de llamar la atención que ni el propio Orozco haya dejado constancia de ello en las interesantes páginas de su Autobiografia. No obstante lo dicho, existen algunas noticias sobre esa temprana producción, las cuales transcribiremos aquí.

La primera exposición de José Clemente Orozco tuvo lugar del $1^{\circ}$ al 20 de septiembre de 1916, en la Librería Biblos de la ciudad de México; la exposición incluía dibujos y caricaturas. Bajo el título de: "Estudios de mujeres", los dibujos se dividían en dos partes. En la primera se reunían los dedicados a cierto tipo de mujeres jóvenes de la ciudad, vistas con un sentido costumbrista no exento de ironía e intencionada picardía. En la segunda parte desfilaban con crudo realismo, las infelices mujeres de los burdeles, las habitantes de las "casas del llanto", como Orozco las calificó. En cuanto a las caricaturas allí expuestas en número de diecisiete, en su mayoría eran de carácter político; con esa crítica incondicional que habría de distinguirle, se encontraban desde el Primer

1 Orozco, forma e idea, p. 29, segunda edición. Editorial Porrúa, México, 1956. 
Jefe (Venustiano Carranza), hasta las Viejitas "revolucionarias". A propósito de la exposición Jean Charlot escribió que:

El hermano de Orozco inauguró ese mismo día su propia obra maestra, el restaurante "Monotes", que fue famoso por su cocina mexicana. El primero de septiembre los amigos de Orozco, después de haber inaugurado la exposición, cenaron alli. El nombre del café provino de los "murales" con los que su hermano Clemente había animado las paredes. La decoración de "Los Monotes" no era una competencia indigna para la exposición. ${ }^{2}$

José Juan Tablada uno de los críticos de arte más eminentes que ha habido en México, cuya obra por desgracia está olvidada, fue el primero en ocuparse del arte de Orozco; Tablada conoció las obras que se mostraban en "Los monotes" y al respecto escribió lo siguiente:

Una obra muy representativa de Orozco se encuentra en uno de los lugares más característicamente mexicanos de la ciudad de México, un café, un lugar de reunión de pintores e intelectuales, llamado Los Monotes, una frase que significa algo como "grandes muñecos". En las noches cuando cierran los teatros circunvecinos, seguramente podrá uno encontrarse con pintores tan famosos como Rivera, Rodríguez Lozano, Charlot y Angel, conversando con los escritores más modernos. A lo largo de las cuatro paredes del pasillo, cubierto por una atmósfera cargada de humo de tabaco y los olores estimulantes de la picante comida mexicana, está un fresco en el cual los personajes de Orozco actúan y bailan enmedio de un frenesi de movimientos y expresión; las chicas del "Follies" flirteando con sus viejos admiradores, parejas paseándose en antiguos carruajes alquilados, policías tan pasivos como los que controlan el tiempo en las peleas de box, y como leimotiv, la joven aventada y llamativa de la clase media o popular de la ciudad, con maquillaje y un peinado elaborado. Si alguien le habla con admiración a Orozco de sus pinturas, obtendrá como única respuesta un rechazo. Su creador está convencido de la mediocridad de sus maravillosas figuras - pintadas sobre cartón, cortadas y pegadas en la pared- a pesar de que las masas asisten a ese lugar para admirar esas alegres pinturas de la vida citadina, más que para tomar el chocolate espumoso, los sabrosos tamales, asi como otros "cuetes" apetecibles de la cocina mexicana. ${ }^{8}$

2 The mexican mural renaissance, 1920-1925, p. 219. Yale University Press, 1963.

8 "José Clemente Orozco, the mexican Goya", en International Studio, vol. 78. núm. 322. New York, marzo de 1924. 
Aparte de Ios dos testimonios transcritos, existe uno más que si bien fue escrito años más tarde no por ello deja de tener cierta validez, puesto que quien lo escribió conoció, sin duda alguna, los dos establecimientos; el autor del tercer testimonio es José Guadalupe Zuno, amigo y paisano de Orozco; suyas son las siguientes líneas:

Las obras eran expuestas en las reducidas paredes de una fonda llamada Los monitos, de la familia de Orozco. Allá de tarde en tarde, algún cliente estrafalario se llevaba, pagando bien, alguno de aquellos cartones iluminados con acuarelas y guaches. La minoria de artistas e intelectuales de aquellos borrascosos días, atraída por los amigos de Orozco, y por las exposiciones, se dio cita en la fondita que así se convirtió en Club Literario y Artístico. Las mesitas de humildísimo ocote y sillas de tule, fueron ocupadas por varios y extraños comensales melenudos que hablaban, gritaban y gesticulaban en largas discusiones. Las veladas se prolongaban hasta la madrugada. Progresó la fonda porque aumentó la clientela. La que pagaba, no, la otra. Y a poco salió un comprador rico. Le gustó el negocio. Trataron, regatearon, llegaron al precio, puso por única condición que la familia no se estableciera con el mismo nombre, se cerró el trato... y pagó. José Clemente encontró algún tiempo después, por ahí cerquita, un local amplio, con grandes paredes blancas. Lo pintó. Colocó sillas y mesas de encino y llenó de cartones grandes con sus temas predilectos. de guaches y acuarelas, aquellos espaciosos muros... y sobre la puerta colocó un gran rótulo: Los MoNotrs ... Corrió la voz. Las minorías selectas de intelectuales y artistas, cambiaron el rumbo y se trasladaron en masa (pequeña masa) al nuevo local. Reanudaron sus interminables charlas en rededor de las mesas de encino y entablaron largas discusiones sobre arte, literatura, política ... y jurisprudencia, para preparar la explicación conveniente al comprador de "Los monitos", demostrando que Clemente no violo el contrato."

Las noticias que ofrecen las tres fuentes son más que suficientes para enterarse del carácter de las obras de Orozco en "Los monotes". Mas antes de ocuparme de las noticias deseo hacer un breve comentario sobre los autores de las mismas. Si Zuno se refiere a los dos establecimientos, se debe a que él vivía en la ciudad de México en esos años, cursaba sus estudios de Derecho; no sucedió lo mismo con Charlot, quien llegó al país en 1921; del propio Orozco, de quien fue gran amigo, debió recoger las noticias que da sobre las inauguraciones, tanto de la exposición como del restaurante. Tal vez el propio Tablada era uno de los asiduos

1 Orozco y la ironia pldstica, pp. 66-67. Cuadernos Americanos. México, 1953. 
"escritores modernos", que concurría al lugar; él escribió su artículo hacia 1924 para ser publicado en inglés en New York, parece ser que el café aún existía en ese año.

Tanto Tablada como Zuno se refieren a que las obras de Orozco que se exhibían en el negocio del hermano, eran dibujos y caricaturas "iluminadas con acuarelas y guaches", hechas en grandes pliegos de cartón, los cuales se fijaban sobre los blancos muros del café; Tablada hace mención de un fresco, e incluso da una descripción sobre el contenido del mismo; pero también habla de "figuras pintadas sobre cartón, cortadas y pegadas a la pared", las cuales "allá de tarde en tarde, al decir de Zuno, algún cliente estrafalario se llevaba pagando bien..." Y Charlot escribió que "la decoración de 'Los monotes' no era competencia indigna para la exposición" de dibujos de Orozco recién abierta.

En fecha reciente al realizar una investigación con otros fines, en la Hemeroteca Nacional encontré en la revista Zig-Zag, las cuatro ilustraciones que aquí se reproducen, sobre las obras de José Clemente Orozco en el café "Los monotes", las fotografías servían de complemento a un artículo que si bien nada tiene que ver con el arte pictórico, sí en cambio lo tiene con el arte culinario y los parroquianos que al café concurrían. ${ }^{5}$

La ilustración que aquí se publica como figura 2, muestra el interior de "Los monotes". En la parte superior del local aparecen unas pinturas con personajes en distintas dimensiones; abajo, inmediatamente, se encuentran dos cuadros pequeños fijados sobre el muro. Lo primero que me pregunté sobre las pinturas grandes, fue si éstas estaban hechas sobre las "grandes paredes blancas" de que habla Zuno, o si se trataba del "fresco" que describió Tablada. Para contestar las preguntas hice varias consultas con personas que conocieron el café, mas por desgracia ninguna pudo recordar y precisar si se trataba de pinturas murales y mucho menos con qué técnica se habían ejecutado; la mayor parte de los entrevistados coincidieron entre sí y con Tablada y Zuno, al afirmar que Orozco llevaba sus dibujos en cartón, que los colgaba de los muros y los desprendía al venderlos. Sin embargo, cabe suponer que si realmente se hubiera tratado de pinturas murales, el propio artista los

5 El artículo se titula "Cosas típicas de nuestro México. Los cafés bohemios. Los cafés literarios"; está firmado por el "Bachiller-Cronista". Vide Zig-Zag. México, abril 21 de 1921, vol. II, núm. 54, pp. 30-31. Se reproducen aquí los pies de los grabados. 


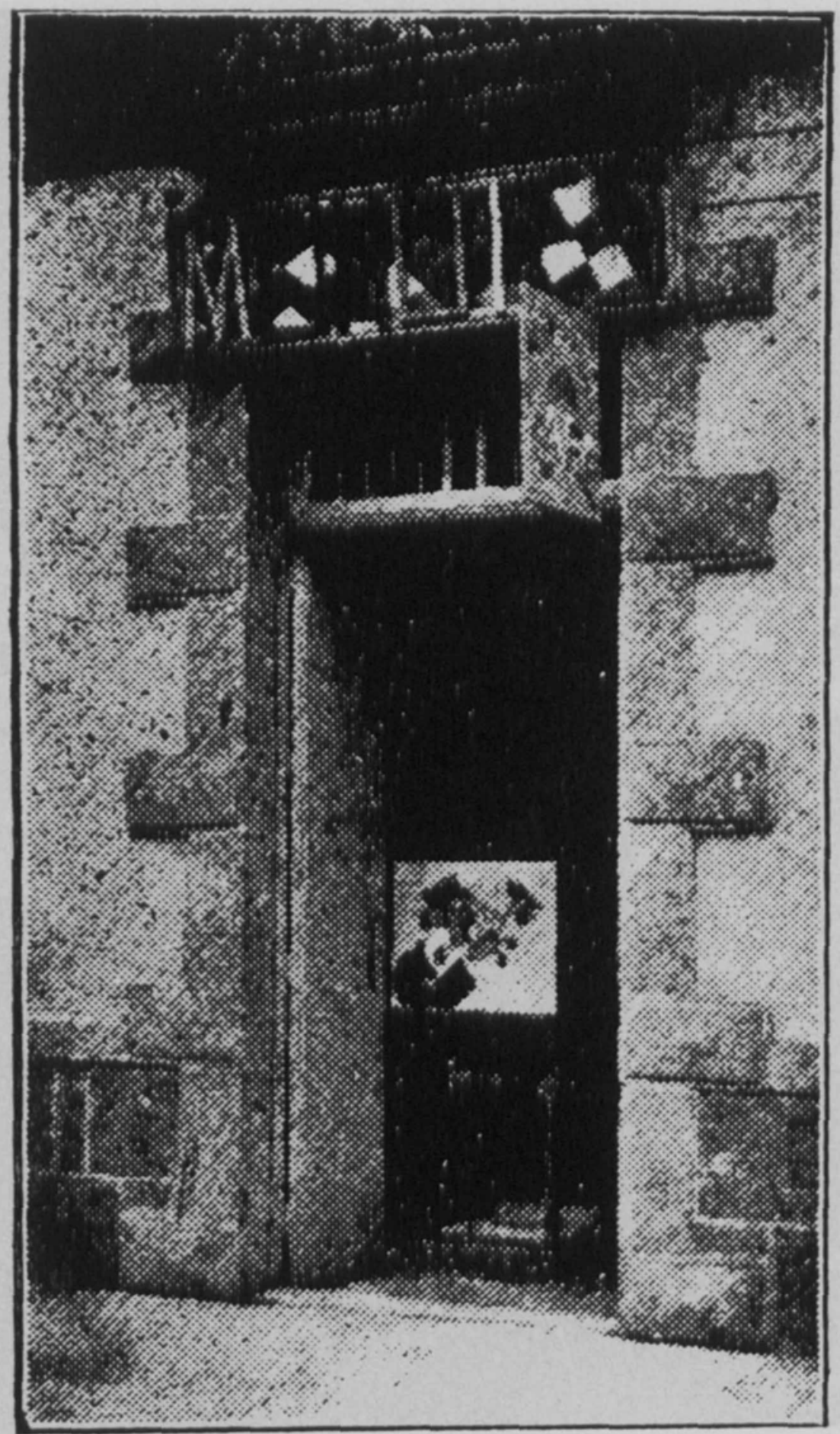

Mezquino es el aspecto exterior de "Los Monotes", que es por hoy el centro de reunión de la bohemia literaria de México, pero es sabido que los émulos de Rodolfo, no son muy exigentes. 


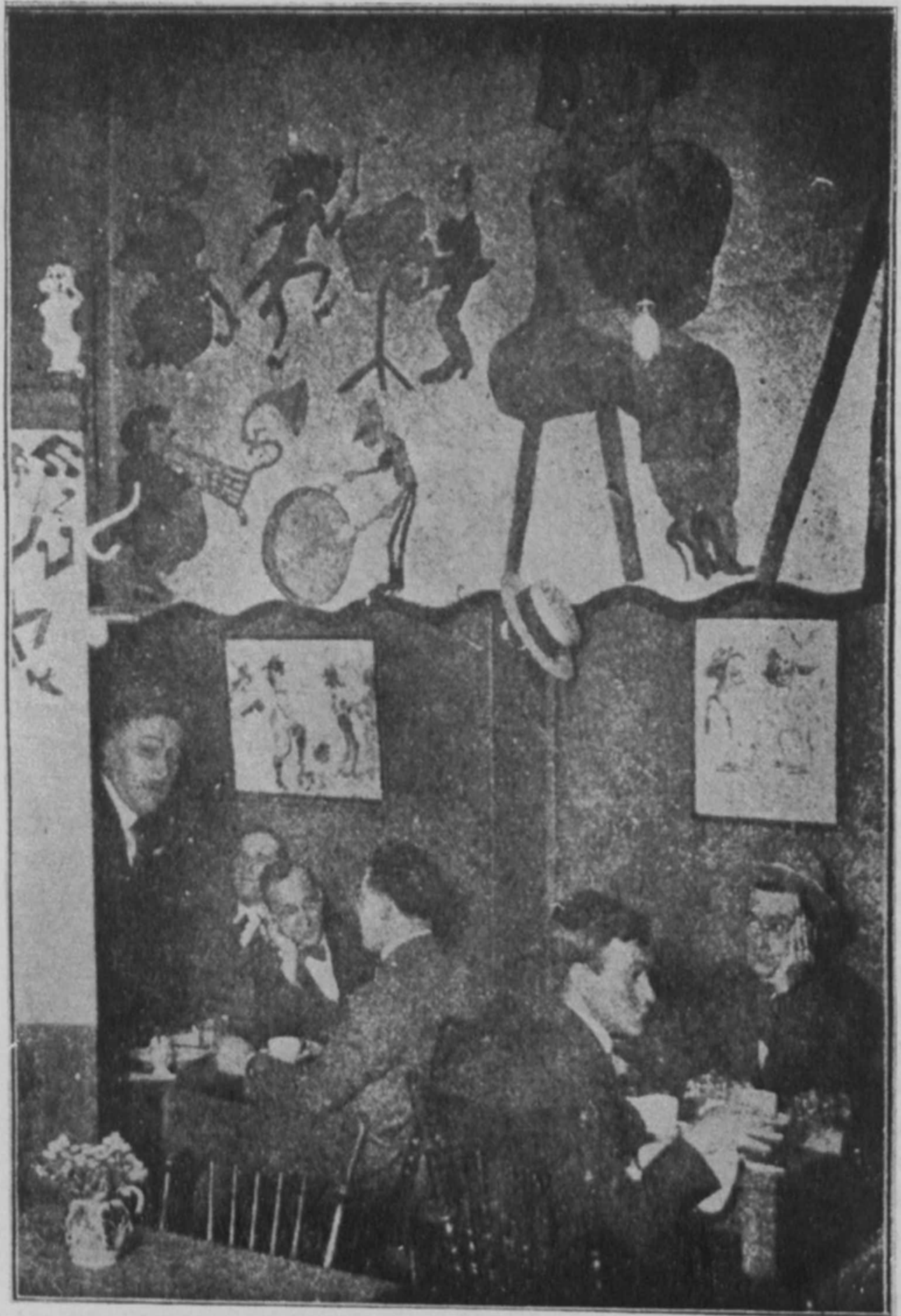

Es la hora en que en "Los Monotes", se reúnen autores teatrales, periodiatas. dibujantes. No son muy espléndidos para consumir, pero si ricos en buen humor y talento. 


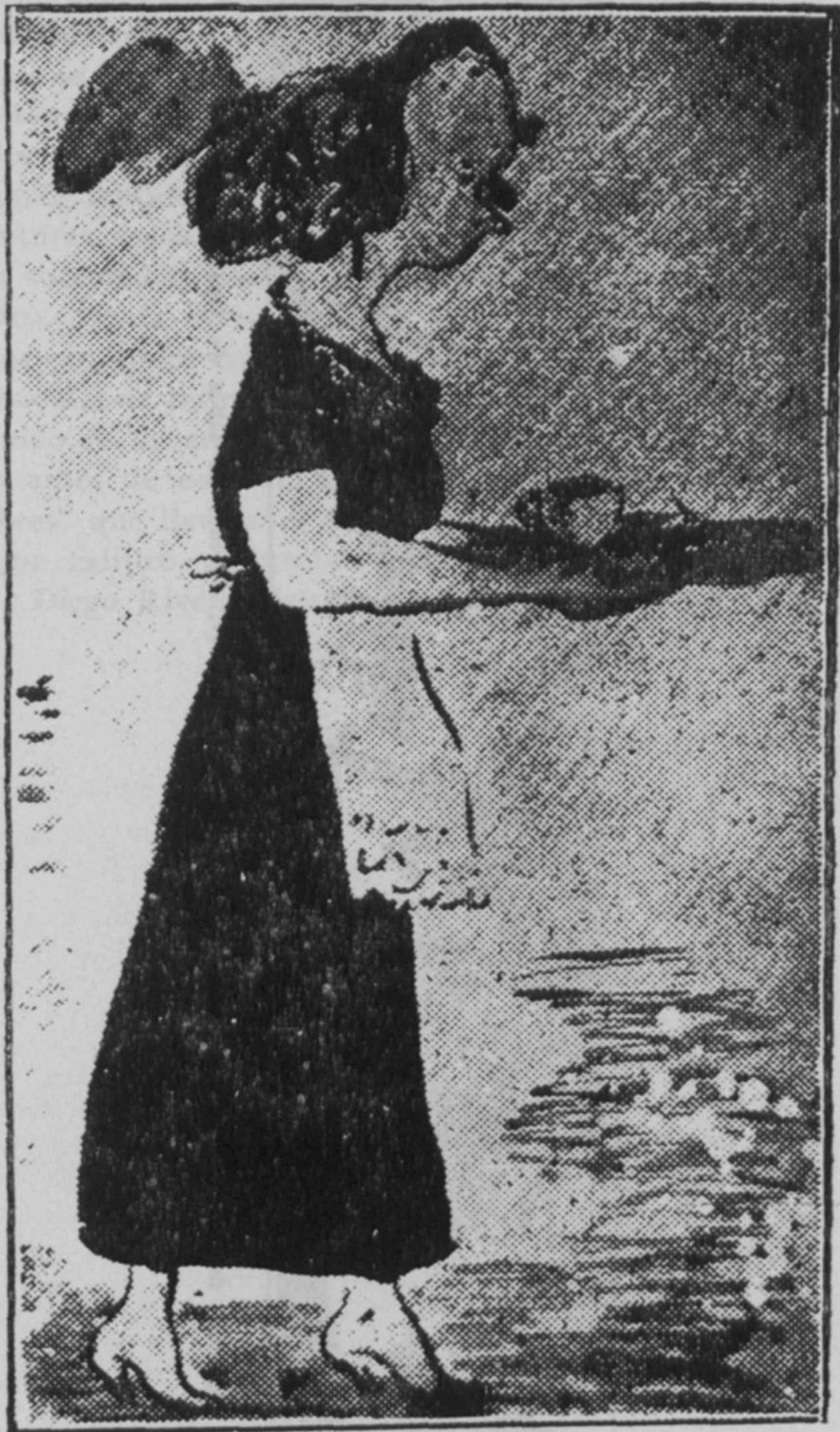

José Clemente Orozco, que ha decorado los muros del café con intencionadas caricaturas, no podía dejar de hacer la de la mesera que sirve $y$ la que reproducimos luce en ana de las paredes. 
DOI: http://dx.doi.org/10.22201/iie.18703062e.1976.46.1064

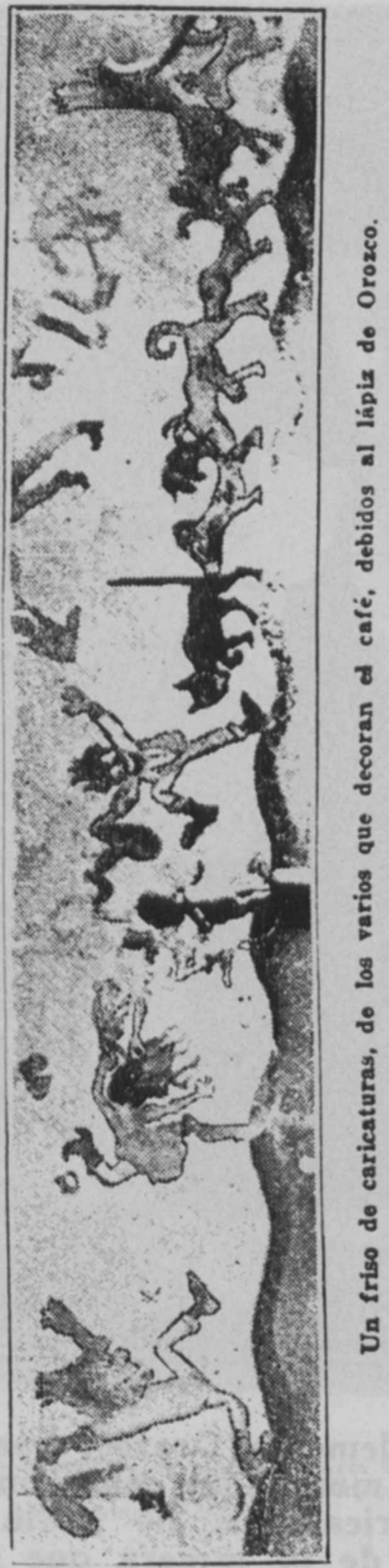


habría citado como los antecedentes más inmediatosi al ciclo de la pintura mural iniciado en el Anfiteatro Bolívar.

Por lo que se puede apreciar en las ilustraciones, las obras de Orozco en "Los monotes", eran de expresión caricaturesca. Corresponden al estilo de los dibujos y caricaturas que hacía en la década de los años diez. El agudo sentido critico que siempre le distinguió, se encontraba en esas pinturas, cuyos temas debieron salir de los tipos más caracteristicos de la sociedad capitalina de la época, temas interpretados en un tono satírico, con la ironía que era tan particular en el artista.

Ojalá que este breve trabajo contribuya en difundir un aspecto poco o nada conocido, de las primeras obras de José Clemente Orozco, aspecto no incluido en los estudios y monografías que sobre él se han publicado. Mas antes de concluir cabe hacer una reflexión: ¿el título de "Los monotes" que llevaba el café fue el que dio lugar a la expresión popular que calificó peyorativamente de "monotes", a los primeros murales de Diego Rivera, del propio Orozco y otros pintores? 